\title{
Modelos de governança corporativa e indicadores econômico-financeiros de Instituições de Educação Superior privadas: uma análise do mercado de capitais brasileiro ${ }^{1}$
}

\author{
Corporate governance models and economic and \\ financial indicators of private Higher Education Institutions: \\ an analysis of the Brazilian capital market
}

\author{
Annor da Silva Junior ${ }^{1}$ \\ Vitor Correa da Silva ${ }^{2}$ \\ Miguel Carlos Ramos Dumer ${ }^{3}$ \\ Priscilla de Oliveira Martins-Silva ${ }^{4}$
}

Resumo: Este artigo tem como escopo a investigação da relação entre modelos de governança corporativa e indicadores econômico-financeiros de entidades mantenedoras de Instituições de Educação Superior presentes no mercado de capitais brasileiro. Para caracterizar os modelos de governança corporativa destas entidades mantenedoras, utilizou-se 12 características definidoras presentes na literatura. Os indicadores econômico-financeiros utilizados foram: liquidez, atividade, endividamento, rentabilidade e mercado. Foi realizada pesquisa documental com dados coletados junto à Comdinheiro e outras fontes. O período investigado foi de sete anos, entre 2013 e 2019, com dados analisados por meio do teste chiquadrado. As evidências indicam a formação de dois grupos, sendo: (1) Grupo A, formado pela YDUQS Participações S.A. e Cogna Educacional S.A. que possuem modelo de governança corporativa tipicamente anglo-saxônico; e (2) Grupo B, formado pela Ânima Holding S.A. e Ser Educacional S.A. que possuem modelo de governança corporativa tipicamente latino-americano. Ao analisar a relação entre estes dois grupos e os indicadores econômico-financeiros, constatou-se que o Grupo A possui (a) menor endividamento e (b) maiores índices de Dividend Yield, quando comparado com o Grupo B. Há evidências de que a governança anglo-saxônica possui potencial para gerar maiores benefícios econômico-financeiros para as entidades mantenedoras que adotam esse modelo.

Palavras-chave: Instituições de educação superior privada. Modelos de governança corporativa. Indicadores econômico-financeiros.

${ }^{1} \mathrm{O}$ projeto de pesquisa que originou a publicação deste artigo recebeu apoio do Conselho Nacional de Desenvolvimento Científico e Tecnológico (CNPq) mediante o Processo no 311291/2020-1; e pela Fundação de Amparo à Pesquisa e Inovação do Espírito Santo (Fapes) mediante o Termo de Outorga no 229/2019. 
Abstract: This paper aims to investigate the relationship between corporate governance models and economic and financial indicators of maintainer entities of Higher Education Institutions present in the Brazilian capital market. To characterize the corporate governance models of these maintainer entities, 12 defining characteristics present in the literature were used. The economic and financial indicators used were: liquidity, activity, indebtedness, profitability and, market. Documental research was carried out with data collected from Comdinheiro and other sources. The period investigated was seven years, between 2013 and 2019, with data analyzed using the chi-square test. The evidence indicates the formation of two groups: (1) Group A, formed by YDUQS Participações S.A., and Cogna Educacional S.A. which have a typically Anglo-Saxon corporate governance model; and (2) Group B, formed by Ânima Holding S.A., and Ser Educacional S.A. which have a typically Latin American corporate governance model. When analyzing the relationship between these two groups and the economic and financial indicators, it was found that Group A has (a) lower indebtedness and (b) higher Dividend Yield rates, when compared to Group B. There is evidence that Anglo-Saxon governance has the potential to generate greater economic and financial benefits for the maintainer entities that adopt this model.

Keywords: Private higher education institutions. Corporate governance models. Economic and financial indicators.

${ }^{1}$ Universidade Federal do Espírito Santo | Programa de Pós-Graduação em Ciências Contábeis | Vitória | ES | Brasil. Contato: annorsj@gmail.com. ORCID: http://orcid.org/0000-0003-4124-5277

${ }^{2}$ Universidade Federal do Espírito Santo | Grupo de Estudos a Educação Superior e a Gestão Universitária | Vitória | ES | Brasil. Contato: vitor_correa@msn.com. ORCID: http://orcid.org/0000-0001-7199-029X

${ }^{3}$ Universidade Federal do Espírito Santo | Programa de Pós-Graduação em Administração |
Vitória | ES | Brasil. Contato: prof.migueldumer@ @mail.com.
ORCID: http://orcid.org/0000-0002-9527-1991
${ }^{4}$ Universidade Federal do Espírito Santo | Programa de Pós-Graduação em Administração |
Vitória | ES | Brasil. Contato: priscillamartinssilva@ @mail.com. ORCID: http://orcid.org/0000-0002-2922-6607

- Recebido em: 23 de março de 2021

- Aprovado em: 26 de abril de 2021

DOI: http://dx.doi.org/10.1590/S1414-40772021000200015

Este é um artigo publicado em acesso aberto sob uma licença Creative Commons https://creativecommons.org/licenses/by-nc/4.0/ 


\section{Introdução}

Ao longo das últimas quatro décadas a educação superior brasileira passou por transformações significativas, das quais podem-se destacar: (1) a expansão, diversificação e mercantilização da educação superior; (2) a alteração no regime tributário das Instituições de Educação Superior (IES) privadas, admitindo a possibilidade de as mantenedoras assumirem a condição de organizações com e sem finalidade lucrativa; (3) a expansão da educação à distância (EAD) na graduação e na pós-graduação; (4) a formulação e implementação de políticas públicas para a educação superior, como por exemplo, o Sistema Nacional de Avaliação da Educação Superior (Sinaes), o Fundo de Investimento Estudantil (Fies), o Programa Universidade para Todos (ProUni) e o Programa de Apoio a Planos de Reestruturação e Expansão das Universidades Federais (Reuni); (5) a expansão do setor privado e encolhimento do setor público; e (6) a chegada das IES privadas ao mercado de capitais brasileiro (BARREYRO, 2008; SILVA JUNIOR et al., 2017a; 2017b; 2020; SALES et al., 2019; SILVA JUNIOR; QUILICE, 2020; BROCH; BRESCHILIARE; BARBOSA-RINALDI, 2020; DINIZ; GOERGEN, 2020; FRITSCH; JACOBUS; VITELLI, 2020). Todas estas mudanças fizeram com que a educação superior brasileira inaugurasse uma nova fase de seu histórico identificado por Silva Junior et al. (2017a) como a "Nova Era" que, teve início no ano de 2005 e perdura até os dias atuais.

Na "Nova Era" (SILVA JUNIOR et al., 2017a), a análise dos principais dados do último Censo da Educação Superior de 2019 indica a presença na educação superior brasileira de 2.608 IES (sendo, 88,42\% de natureza privada), de 40.427 cursos de graduação presencial e EAD (sendo que, 73,50\% são ofertados em IES privadas) e 8.603 .824 matrículas em cursos de graduação nas modalidades presencial e EAD (sendo que, 75,82\% são em IES privadas) (INEP, 2020). De uma forma geral, esses dados do Censo de 2019 indicam o amplo predomínio do setor privado na educação superior brasileira (SILVA JUNIOR et al., 2017a; INEP, 2020; BROCH; BRESCHILIARE; BARBOSA-RINALDI, 2020).

De todas as transformações observadas na educação superior brasileira, as atenções deste artigo voltam-se para a chegada das entidades mantenedoras de IES ao mercado de capitais brasileiro (atual Brasil Bolsa Balcão $-[B]^{3}$ ). No ano de 2007 ocorreram as primeiras iniciativas de abertura de capital das mantenedoras de IES por meio do Initial Public Offering - IPO (termo em inglês que se refere a Oferta Pública Inicial) junto à antiga Bolsa de Mercadorias e Futuros Bovespa (BM\&FBovespa). Neste ano houveram os IPO da Anhanguera Educacional S.A. (aqui identificada apenas como Anhanguera), da Estácio Participações S.A. (atualmente, YDUQS Participações S.A. e aqui identificada como YDUQS) e da Kroton 
Educacional S.A. (atualmente, Cogna Participações S.A. e identificada como Cogna) (SILVA JUNIOR et al., 2017b; 2020).

Mais tarde, no ano de 2013 fizeram o IPO a Ânima Holding S.A. (identificada como Ânima) e a Ser Educacional S.A. (identificada como Ser). Neste mesmo ano, a Anhanguera foi adquirida pela Cogna. Com todos estes movimentos de $I P O$ e de aquisição, o setor educacional superior passou a contar com quatro companhias, permanecendo assim até os dias atuais. Estas quatro entidades mantenedoras de IES (Ânima, Cogna, Ser e YDUQS) concentram aproximadamente $26 \%$ do total de matrículas em cursos de graduação na educação superior (SILVA JUNIOR et al., 2017b).

A chegada destas entidades mantenedoras de IES ao mercado de capitais brasileiro e a concentração de aproximadamente 2.236.995 de matrículas totais em cursos de graduação são considerados fatores relevantes e motivadores para que se investigue como estas entidades mantenedoras de IES são gerenciadas e, com isso, compreender melhor a gestão corporativa e educacional (GAMA; SANTOS, 2020) dessas companhias. Neste contexto, a governança corporativa (HART, 1995; SILVA JUNIOR; MUNIZ; MARTINS, 2009; ROSSETTI; ANDRADE, 2014) é vista como um aspecto fundamental para a gestão universitária (LAMARRA; BRÁ, 2004) destas companhias.

Historicamente, os estudos sobre governança corporativa tiveram como marco fundamental os trabalhos de Berle e Means (2010) realizados nos anos de 1930 quando analisaram o surgimento da moderna sociedade anônima. As preocupações com esta temática se popularizaram nos anos de 1990 e 2000 quando os escândalos corporativos envolvendo a Enron e a WorldCom nos Estados Unidos da América (EUA) e a Royal Ahold e a Parmalat na Europa ganharam notoriedade no cenário corporativo mundial (MILLAR et al., 2005; BRENES; MADRIGAL; REQUENA, 2011). Mais recentemente, no ano de 2014 o caso da companhia brasileira Petrobras também chamou a atenção do universo corporativo mundial, pela ausência de mecanismos de governança corporativa que pudessem impedir o uso da companhia para fins políticos e sua expropriação por parte de gestores e agentes públicos (LIMA et al., 2017).

Desde a sua origem, as discussões acerca da governança corporativa tiveram como fundamento central a teoria de agência (JENSEN; MECKLING, 1976). Esta perspectiva teórica que foi concebida no contexto anglo-saxônico, assume que o relacionamento de agência é regulado por meio de um contrato (formal ou informal), segundo o qual o principal (representante da estrutura de propriedade) contrata um agente (representante da estrutura de 
gestão) para executar serviços em seu nome, o que envolve delegação de autoridade para tomada de decisão gerencial para o agente (JENSEN; MECKLING, 1976).

Ao longo dos anos, a utilização da teoria de agência (JENSEN; MECKLING, 1976) no âmbito das discussões sobre governança corporativa foi permeada por evoluções e críticas, sobretudo, em termos de sua aplicação em distintos contextos internacionais (LA PORTA; LOPEZ-DE-SILANEZ; SHLEIFER 1999; GOMEZ-MEJIA; WISEMAN; DYKES, 2005). Dentre as diversas possibilidades de aplicações internacionais, destaca-se neste artigo dois modelos distintos: (1) o anglo-saxônico que é considerado o original e é aplicada em países como EUA e Reino Unido; e (2) o latino-americano que é uma variação da concepção original e é aplicado em países como Argentina, Brasil e Chile (ROSSETTI; ANDRADE, 2014).

Para analisar as diferenças entre esses modelos, Rossetti e Andrade (2014) propõem características definidoras de governança corporativa. De uma forma sintética, enquanto (1) o modelo anglo-saxônico se caracteriza pela (a) pulverização da estrutura de propriedade, (b) dissociação entre a propriedade e a gestão, (c) controle da companhia sendo exercido pelo Chief Executive Officer (CEO), e (d) problema de agência do tipo I, cujo conflito ocorre entre o principal e o agente; (2) o modelo latino-americano possui como características centrais (a) concentração da estrutura de propriedade, (b) sobreposição entre a propriedade e a gestão, (c) controle da companhia sendo exercido pelo acionista majoritário, e (d) problema de agência do tipo II, cujo conflito ocorre entre principais, ou seja, entre acionistas majoritários e minoritários.

Embora estes modelos sejam típicos de companhias presentes nos contextos anglosaxônico e latino-americano, é possível que uma companhia brasileira adote, mesmo que parcialmente, características do modelo anglo-saxônico ou latina-americano e vice-versa. Diante das possibilidades que as companhias têm em adotar um ou outro modelo, uma questão que se coloca diz respeito a qual modelo seria mais efetivo? Uma forma de avaliar a efetividade da governança corporativa praticada pelas companhias é por meio de indicadores econômicofinanceiros (ASSAF NETO, 2020).

Conforme destaca Assaf Neto (2020), diversos são os indicadores econômicofinanceiros presentes na literatura. Deste conjunto, pode-se destacar os indicadores (1) de liquidez, que avaliam a capacidade de pagamento de uma companhia diante de suas obrigações; (2) de atividade, que mede o desempenho da companhia a partir do seu ciclo operacional; (3) de endividamento e de estrutura de capital, que permitem analisar, entre outros aspectos, a posição de endividamento e a capacidade de companhia de gerar caixa suficiente para os juros e o principal de suas dívidas; (4) de rentabilidade, que avalia os lucros da companhia em relação a um dado nível de vendas, ativos e capital investido; e (5) de mercado, representado por 
cálculos efetuados a partir das demonstrações financeiras, das cotações e dos proventos (ASSAF NETO, 2020).

Com fundamento nestas considerações e evidências de natureza teórica e empírica, e como forma de avaliar os modelos de governança corporativa das companhias investigadas, a presente pesquisa será conduzida para responder ao seguinte problema de pesquisa: Qual é a relação entre os modelos de governança corporativa e os indicadores econômicofinanceiros de entidades mantenedoras de Instituições de Educação Superior presentes no mercado de capitais brasileiro? Definiu-se como objetivo geral da identificar a relação entre os modelos de governança corporativa e os indicadores econômico-financeiros de entidades mantenedoras de IES presentes no mercado de capitais brasileiro.

Do ponto de vista metodológico, a pesquisa se configura como documental (PAYNE; PAYNE, 2004; MOGALAKWE, 2006). Os dados das quatro companhias (entidades mantenedoras de IES) que compõem o setor da educação superior brasileiro na $[\mathrm{B}]^{3}$ foram coletados por meio de triangulação de dados (DENZIN, 1989; JENSEN; JANKOWSKI, 1993). Foram analisadas a configuração de governança corporativa das instituições com vistas a identificar características relativas ao modelo anglo-saxônico e/ou latino-americano (ROSSETTI; ANDRADE, 2014). Além disso, foram mensurados cinco indicadores econômico-financeiros, quais sejam, de liquidez, de atividade, de endividamento, de rentabilidade e de mercado (ASSAF NETO, 2020).

Com vistas a alcançar maior comparabilidade entre as companhias investigadas, analisou-se o período de 7 anos, entre 2013 a 2019. Justifica-se a escolha deste período pelo fato de o ano de 2013 ter sido o primeiro ano em que as 4 instituições negociaram, simultaneamente, ações no mercado de capitais brasileiro. Para a análise dos dados recorreu-se ao procedimento do teste de chi-quadrado (FÁVERO et al., 2009).

Estruturou-se o artigo em cinco seções além desta introdução. Nas próximas duas seções, são apresentados os aspectos teóricos relativos à governança corporativa e aos indicadores econômico-financeiros. Na quarta seção, apresenta-se os procedimentos metodológicos adotados na pesquisa. Na quinta seção, são apresentados, respectivamente, a apresentação e discussão dos resultados e, por fim, na sexta seção, as conclusões. 


\section{Governança corporativa: conceito e modelos anglo-saxônico e latino-americano}

Diversas são as definições de governança corporativa presentes na literatura (ROSSETTI; ANDRADE, 2014). Do conjunto de definições, adotou-se neste estudo a visão de Blair (1995, p. 3, tradução nossa) que concebe a governança corporativa como "todo o conjunto legal, cultural e institucional que determina o que as companhias de capital aberto podem fazer, quem as controla, como o controle é exercido, e como os riscos e retornos das atividades são alocados". Optou-se por adotar esta definição por estar mais alinhada com as características das quatro entidades mantenedoras de IES investigadas que se configuram como companhias abertas listadas na $[\mathrm{B}]^{3}$.

Conforme já destacado anteriormente, a utilização da teoria de agência (JENSEN; MECKLING, 1976) para ancorar as discussões sobre governança corporativa permite a identificação de distintos modelos de governança corporativa conforme o contexto internacional (LA PORTA; LOPEZ-DE-SILANEZ; SHLEIFER 1999; GOMEZ-MEJIA; WISEMAN; DYKES, 2005). Neste estudo, o escopo volta-se para os modelos anglo-saxônico e latino-americano (ROSSETTI; ANDRADE, 2014). Apoiado nas contribuições de Rossetti e Andrade (2014) adotou-se neste estudo 12 características definidoras de governança corporativa conforme destacado no Quadro 1. Estas características definidoras permitem identificar como se configuram os modelos anglo-saxônico e latino-americano. 
Quadro 1 - Doze Características Definidoras de Governança Corporativa

\begin{tabular}{|c|c|c|}
\hline $\mathbf{N}^{\mathbf{0}}$ & Características & Considerações \\
\hline 1 & $\begin{array}{l}\text { Segmento de } \\
\text { listagem }\end{array}$ & $\begin{array}{l}\text { Refere-se aos segmentos de listagens adotados pela }[\mathrm{B}]^{3} \text { com regras próprias de } \\
\text { governança corporativa. Esses segmentos são: Bovespa Mais, Bovespa Mais } \\
\text { Nível 2, Novo Mercado, Nível } 2 \text { e Nível 1. }\end{array}$ \\
\hline 2 & $\begin{array}{l}\text { Composição } \\
\text { acionária }\end{array}$ & $\begin{array}{l}\text { Refere-se à forma como as ações estão distribuídas entre os detentores do capital } \\
\text { da companhia. Pode indicar uma maior ou menor concentração da estrutura de } \\
\text { propriedade. }\end{array}$ \\
\hline 3 & $\begin{array}{l}\text { Fonte predominante } \\
\text { de financiamento }\end{array}$ & $\begin{array}{l}\text { As principais fontes de financiamento são do tipo debt por meio de } \\
\text { endividamento ou capital de terceiros ou do tipo equity via emissão de ações ou } \\
\text { capital próprio. }\end{array}$ \\
\hline 4 & $\begin{array}{lrl}\text { Relação entre } & \text { a } \\
\text { propriedade } & \text { e } & \text { o } \\
\text { controle } & & \end{array}$ & $\begin{array}{l}\text { É uma decorrência da composição acionária. Em companhia cuja propriedade é } \\
\text { mais concentrada, o controle é exercido pelo acionista. Quando há maior } \\
\text { pulverização da propriedade o controle é exercido pelo CEO. }\end{array}$ \\
\hline 5 & 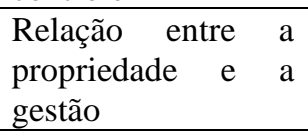 & $\begin{array}{l}\text { Essa relação decorre da composição acionária. A propriedade e a gestão podem } \\
\text { ser sobrepostas (quando há maior concentração) ou dissociadas (quando há maior } \\
\text { pulverização do controle acionário). }\end{array}$ \\
\hline 6 & $\begin{array}{l}\text { Tipologia do } \\
\text { conflito de agência }\end{array}$ & $\begin{array}{l}\text { Essa tipologia decorre da concentração ou pulverização da propriedade e controle } \\
\text { da companhia. O conflito de agência pode ser (1) do tipo I (típico de companhias } \\
\text { com maior pulverização da propriedade), que envolve a relação de conflitos de } \\
\text { interesses entre o principal (acionista) e o agente (CEO); ou (2) do tipo II (típico } \\
\text { de companhias com maior concentração da propriedade), que envolve a relação } \\
\text { de conflitos de interesses entre principais, no caso, os acionistas majoritários e } \\
\text { minoritários. }\end{array}$ \\
\hline 7 & $\begin{array}{l}\text { Proteção legal dos } \\
\text { minoritários }\end{array}$ & $\begin{array}{l}\text { Refere-se aos instrumentos normativos (legais e infralegais) que determinam a } \\
\text { forma de proteção dada aos acionistas minoritários. }\end{array}$ \\
\hline 8 & $\begin{array}{ll}\text { Composição } & \text { do } \\
\text { conselho } & \text { de } \\
\text { administração } & \\
\end{array}$ & $\begin{array}{l}\text { Identifica o tamanho e a composição do conselho de administração } \\
\text { (representantes dos interesses da estrutura de propriedade). }\end{array}$ \\
\hline 9 & $\begin{array}{l}\text { Liquidez de } \\
\text { participação } \\
\text { acionária }\end{array}$ & $\begin{array}{l}\text { Refere-se a liquidez na negociação de ações no mercado de capitais. Quanto } \\
\text { maior a concentração da propriedade, menor tende a ser a liquidez da participação } \\
\text { acionária e quanto maior for a pulverização das ações, maior tende a ser a liquidez } \\
\text { da participação acionária. }\end{array}$ \\
\hline 10 & $\begin{array}{l}\text { Forças de controle } \\
\text { mais atuantes }\end{array}$ & $\begin{array}{l}\text { Refere-se ao exercício do controle da companhia. Podem ser (1) externas, ou seja, } \\
\text { de mercado, quando as ações forem pulverizadas e com maior liquidez; ou (1) } \\
\text { internas, decorrentes da concentração da propriedade, quando o controle da } \\
\text { companhia é exercido pelo acionista majoritário e controlador. }\end{array}$ \\
\hline 11 & $\begin{array}{l}\text { Orientação } \\
\text { modelo } \\
\text { governança }\end{array}$ & $\begin{array}{l}\text { Refere-se a orientação do modelo de governança corporativa cujo foco volta-se } \\
\text { para os acionistas (shareholders) ou para as demais partes interessadas } \\
\text { (stakeholders). A orientação pode ser (1) restrita, para atender os interesses dos } \\
\text { acionistas (shareholders) ou (2) ampla, para atender um conjunto maior de partes } \\
\text { interessadas (stakeholders). }\end{array}$ \\
\hline 12 & $\begin{array}{l}\text { Remuneração } \\
\text { executivos }\end{array}$ & $\begin{array}{l}\text { Representa um mecanismo utilizado pela estrutura de propriedade (principal) } \\
\text { para monitorar e controlar as atividades do executivo (agente). }\end{array}$ \\
\hline
\end{tabular}

Fonte: Adaptado de Rossetti e Andrade (2014).

De acordo com Rossetti e Andrade (2014) a utilização destas características definidoras permite identificar a configuração dos modelos anglo-saxônico e latino-americano de governança corporativa, que podem ser sintetizados por meio do Quadro 2. Estas características são consideradas típicas de cada uma destes dois contextos internacionais. 
Quadro 2 - Configuração dos Modelos Anglo-Saxônico e Latino-Americano de Governança Corporativa

\begin{tabular}{|c|c|c|c|}
\hline $\mathbf{N}^{\mathbf{0}}$ & Características & Modelo Anglo-Saxônico & Modelo Latino-Americano \\
\hline 1 & Segmento de listagem & $\begin{array}{l}\text { Relativo (depende da escolha e do } \\
\text { perfil da companhia) }\end{array}$ & $\begin{array}{l}\text { Relativo (depende da escolha da e do } \\
\text { perfil da companhia) }\end{array}$ \\
\hline 2 & Composição acionária & $\begin{array}{l}\text { Pulverizado com menor concentração } \\
\text { da propriedade }\end{array}$ & $\begin{array}{l}\text { Propriedade concentrada (em muitos } \\
\text { casos, no âmbito de companhias } \\
\text { familiares) }\end{array}$ \\
\hline 3 & $\begin{array}{l}\text { Fonte predominante de } \\
\text { financiamento }\end{array}$ & Equity & Debit \\
\hline 4 & $\begin{array}{lrr}\text { Relação entre } & \text { a } \\
\begin{array}{l}\text { propriedade } \\
\text { controle }\end{array} & \text { e } & \text { o } \\
\end{array}$ & Controle exercido pelo CEO & $\begin{array}{c}\text { Controle exercido pelo acionista } \\
\text { majoritário }\end{array}$ \\
\hline 5 & $\begin{array}{l}\text { Relação entre a } \\
\text { propriedade e a gestão }\end{array}$ & $\begin{array}{l}\text { Dissociação entre a propriedade e a } \\
\text { gestão }\end{array}$ & $\begin{array}{l}\text { Sobreposição entre a propriedade e a } \\
\text { gestão }\end{array}$ \\
\hline 6 & $\begin{array}{l}\text { Tipologia do conflito de } \\
\text { agência }\end{array}$ & $\begin{array}{l}\text { Tipo I, conflito de interesses entre o } \\
\text { principal e o agente }\end{array}$ & $\begin{array}{l}\text { Tipo II, conflito de interesses entre } \\
\text { principais (acionistas majoritário e } \\
\text { minoritário) }\end{array}$ \\
\hline 7 & $\begin{array}{l}\begin{array}{l}\text { Proteção legal dos } \\
\text { minoritários }\end{array} \\
\end{array}$ & Forte & Relativo, com tendência a ser fraca \\
\hline 8 & $\begin{array}{ll}\text { Composição } & \text { do } \\
\text { conselho } & \text { de } \\
\text { administração } & \\
\end{array}$ & $\begin{array}{l}\text { Dispersa, independente e com foco } \\
\text { em direitos }\end{array}$ & $\begin{array}{l}\text { Concentrado e com vínculos com a } \\
\text { gestão }\end{array}$ \\
\hline 9 & $\begin{array}{l}\text { Liquidez de } \\
\text { participação acionária }\end{array}$ & Alta & Especulativa e oscilante \\
\hline 10 & $\begin{array}{l}\text { Forças de controle mais } \\
\text { atuantes }\end{array}$ & Externas (mercado) & Internas (controle da propriedade) \\
\hline 11 & $\begin{array}{l}\text { Orientação do modelo } \\
\text { de governança }\end{array}$ & Shareholder (acionistas) & Shareholder (acionistas) \\
\hline 12 & $\begin{array}{l}\text { Remuneração } \\
\text { executivos }\end{array}$ & $\begin{array}{l}\text { Voltada para o controle do agente } \\
\text { (gestor) }\end{array}$ & $\begin{array}{c}\text { Voltada para o benefício e interesses } \\
\text { do principal }\end{array}$ \\
\hline
\end{tabular}

Fonte: Adaptado de Rossetti e Andrade (2014).

É com base nestas configurações dos modelos anglo-saxônico e latino-americano que serão analisadas as características das quatro companhias listadas na $[\mathrm{B}]^{3}$ (entidades mantenedoras de IES) e que fazem parte do setor da educação superior no mercado de capitais brasileiro. A partir destas características será possível identificar se estas companhias adotam uma configuração mais próxima de um ou de outro modelo internacional de governança corporativa. 


\section{Indicadores econômico-financeiros}

Um dos aspectos centrais na gestão corporativa das companhias é a avaliação (e mensuração) de desempenho. Para isso, as companhias recorrem a um conjunto de indicadores capazes de refletir os efeitos (positivos e/ou negativos) do processo gerencial e de tomada de decisões (BENIN; DIEHL; MARQUEZAN, 2019). De acordo com Marquezan, Diehl e Alberton (2013) e Benin, Diehl e Marquezan (2019), os indicadores utilizados pelas companhias podem ser de origem interna ou externa e possuem natureza quantitativa (indicadores econômico-financeiros) e qualitativa (indicadores não econômico-financeiros). No presente estudo, o foco volta-se para os indicadores econômico-financeiros de origem interna (contábil) e externa (mercado).

Segundo Silva (2017), uma forma para se obter uma visão mais abrangente da situação econômica, financeira e patrimonial de uma entidade é por meio da apuração de indicadores econômico-financeiros. Conforme apontam Teixeira e Melo (2011), estes indicadores cumprem o papel de demonstrar as potencialidades de uma entidade, uma vez que informam, entre outros aspectos, (1) a liquidez para dispor de recursos para saldar dívidas; (2) o endividamento junto a terceiros; e (3) o retorno sobre os investimentos dos acionistas, ou seja, a lucratividade.

Na visão de Iudícibus (2009), a principal finalidade do uso de indicadores econômicofinanceiros é permitir que os usuários da contabilidade possam extrair tendências e comparar os quocientes com padrões previamente estabelecidos, reportando, com isso, as evidências do que ocorreu no passado e gerando projeções para resultados futuros. Neste estudo, serão utilizados os indicadores econômico-financeiros apontados por Assaf Neto (2020) para análise de uma companhia, quais sejam, de liquidez, de atividade, de endividamento, de rentabilidade e de mercado. A descrição e a forma de mensuração destes indicadores serão apresentadas mais adiante por meio do Quadro 4 na próxima seção.

\section{Método}

Metodologicamente, o estudo se configura como pesquisa documental (PAYNE; PAYNE, 2004; MOGALAKWE, 2006). Este tipo de pesquisa se caracteriza pela utilização de fontes documentais diversas no âmbito da pesquisa social (MOGALAKWE, 2006).

A coleta de dados foi realizada por meio de triangulação (DENZIN, 1989; JENSEN; JANKOWSKI, 1993) por envolver a busca de documentos em diferentes fontes considerando as dimensões temporal, espacial e analítica (JENSEN; JANKOWSKI, 1993; DENZIN, 1989). Como fonte documental foram utilizados os sítios na internet das companhias (entidades mantenedoras de IES), da $[\mathrm{B}]^{3}$, da CVM, do Ministério da Educação (MEC) e do Instituto 
Nacional de Estudos e Pesquisas Educacionais Anísio Teixeira (Inep), bem como outras informações disponíveis na base de dados Comdinheiro.

Os documentos consultados foram os relatórios de administração, as demonstrações contábeis, as notas explicativas, os Formulários de Referências, entre outros. O horizonte temporal da pesquisa foi de sete anos, compreendendo os anos de 2013 a 2019. O Quadro 3 destaca informações relativas às quatro companhias (entidades mantenedoras de IES) que compõem o setor de educação superior na $[\mathrm{B}]^{3}$.

\section{Quadro 3 - Entidades Mantenedoras de IES (Companhias) Presentes no Setor da Educação Superior na} $[B]^{3}$

\begin{tabular}{|l|l|l|l|}
\hline $\mathbf{N}^{\mathbf{1}}$ & \multicolumn{1}{|c|}{$\begin{array}{c}\text { Companhias } \\
\text { (mantenedoras) }\end{array}$} & \multicolumn{1}{|c|}{ Site Institucional } & \multicolumn{1}{|c|}{ IES (mantidas) } \\
\hline 1 & Ânima & https://ri.animaeducacao.com.br/ & $\begin{array}{l}\text { Universidade São Judas Tadeu, Una, } \\
\text { UniBH, entre outras }\end{array}$ \\
\hline 2 & Cogna & http://ri.cogna.com.br & $\begin{array}{l}\text { Anhanguera, Pitágoras, Unopar, entre } \\
\text { outras }\end{array}$ \\
\hline 3 & Ser & http://ri.sereducacional.com/ & $\begin{array}{l}\text { UniNassau, Faculdade Joaquim } \\
\text { Nabuco, Unama, entre outras }\end{array}$ \\
\hline 4 & YDUQS & https://www.yduqs.com.br/ & $\begin{array}{l}\text { Universidade Estácio de Sá, } \\
\text { Faculdades Estácio de Sá, entre outras }\end{array}$ \\
\hline
\end{tabular}

Fonte: Dados da pesquisa.

Como forma de análise de dados, procedeu-se a análise qualitativa das 12 características definidoras da governança corporativa das companhias investigadas e, conforme será melhor explicado na apresentação dos resultados, foi possível discriminá-las em 2 grupos, cada um composto por 2 companhias com características de governança semelhantes entre elas, mas diferentes das companhias do outro grupo. Estes dois grupos refletiram as características dos modelos de governança corporativa anglo-saxônico ou latino-americano. Posteriormente, mensurou-se, seguindo as indicações de Assaf Neto (2020), os indicadores econômicofinanceiros das quatro instituições. Os indicadores são apresentados no Quadro 4. 
Quadro 4 - Indicadores Econômico-financeiros

\begin{tabular}{|c|c|c|c|}
\hline $\mathbf{N}^{\mathbf{0}}$ & Indicador & Descrição & $\begin{array}{l}\text { Fundamenta- } \\
\text { ção Teórica }\end{array}$ \\
\hline 1 & Indicadores de liquidez & $\begin{array}{l}\text { Avaliam a capacidade de pagamento da } \\
\text { companhia frente às suas obrigações }\end{array}$ & \multirow{21}{*}{$\begin{array}{l}\text { Assaf Neto } \\
\quad(2020)\end{array}$} \\
\hline 1.1 & Índice de liquidez corrente & ativo circulante/passivo circulante & \\
\hline 1.2 & Índice de liquidez imediata & disponibilidades/passivo circulante & \\
\hline 1.3 & Índice de liquidez geral & $\begin{array}{l}\text { (ativo circulante + realizável a longo prazo) / } \\
\text { (passivo circulante + exigível a longo prazo) }\end{array}$ & \\
\hline 2 & Indicadores de atividade & $\begin{array}{l}\text { Servem para medir o desempenho da companhia } \\
\text { a partir do seu ciclo operacional }\end{array}$ & \\
\hline 2.1 & $\begin{array}{l}\text { Prazo médio de recebimento de } \\
\text { vendas }\end{array}$ & contas a receber/(vendas líquidas/360) & \\
\hline 3 & $\begin{array}{l}\text { Indicadores de endividamento e } \\
\text { de estrutura de capital }\end{array}$ & $\begin{array}{c}\text { Servem para analisar a posição de } \\
\text { endividamento, a capacidade da companhia gerar } \\
\text { caixa suficiente para os juros e o principal de } \\
\text { suas dívidas e/ou garantir o crescimento de suas } \\
\text { atividades }\end{array}$ & \\
\hline 3.1 & $\begin{array}{l}\text { Relação de capital de terceiros e } \\
\text { ativo total }\end{array}$ & passivo total/ativo total & \\
\hline 3.2 & Imobilização de recursos & $\begin{array}{c}\text { ativo permanente/(exigível a longo prazo + } \\
\text { patrimônio líquido) }\end{array}$ & \\
\hline 4 & Indicadores de rentabilidade & $\begin{array}{c}\text { Servem para avaliar os lucros da companhia em } \\
\text { relação a um dado nível de vendas, ativos e } \\
\text { capital investido }\end{array}$ & \\
\hline 4.1 & Retorno sobre o ativo (ROA) & lucro operacional/ativo total & \\
\hline 4.2 & $\begin{array}{l}\text { Retorno sobre os investimentos } \\
(\mathrm{ROI})\end{array}$ & $\begin{array}{l}\text { lucro operacional/(passivo oneroso + patrimônio } \\
\text { líquido) }\end{array}$ & \\
\hline 4.3 & $\begin{array}{l}\text { Retorno sobre o patrimônio líquido } \\
\text { (ROE) }\end{array}$ & lucro líquido/patrimônio líquido. & \\
\hline 4.4 & Margem Operacional & lucro operacional/receita líquida. & \\
\hline 4.5 & Margem Líquida & lucro líquido/receita líquida. & \\
\hline 5 & Indicadores de mercado & $\begin{array}{l}\text { São cálculos efetuados com dados extraídos dos } \\
\text { demonstrativos financeiros, das cotações e dos } \\
\text { proventos }\end{array}$ & \\
\hline 5.1 & Lucro por ação & lucro líquido $/ \mathrm{n}^{\circ}$ de ações emitidas & \\
\hline 5.2 & Índice preço-lucro & preço da ação/lucro por ação & \\
\hline 5.3 & Índice Preço-Valor patrimonial & preço da ação/valor patrimonial por ação & \\
\hline 5.4 & Dividend Yield & proventos pagos por ação/valor da ação & \\
\hline 5.5 & Payout & proventos pagos/lucro líquido & \\
\hline
\end{tabular}

Fonte: Elaborado pelos autores.

Nota: Não se utilizou o índice de liquidez seca em virtude de as companhias serem prestadoras de serviços educacionais e, portanto, não possuírem estoques. Neste aspecto, ressalta-se que a Cogna é uma exceção, visto que possui uma controlada que é editora. Como as demais companhias não possuem tal aspecto, optou-se por não incluir esse índice na análise. Pelo mesmo motivo, excluiu-se da análise os indicadores de prazo médio de estocagem e de pagamento à fornecedores. 
Os indicadores evidenciados no Quadro 4 foram mensurados no horizonte temporal de 7 anos (entre 2013 e 2019), totalizando 28 observações por companhia/ano para cada indicador mensurado (4 companhias X 7 anos). Considerando que a amostra não possuía mais de 30 observações e que não foi identificada a normalidade e a homogeneidade das variâncias nos dados, percebeu-se que testes estatísticos paramétricos, como a análise de variância e a regressão, além de alguns testes de hipóteses, não deveriam ser operacionalizados, sendo, nestes casos, mais adequado o uso de testes não paramétricos (FÁ́VERO et al., 2009). Portanto, dado as características da amostra, optou-se por categorizar os indicadores econômico-financeiros para identificar a relação dos 2 grupos de governança corporativa definidos com cada um dos indicadores por meio do teste não paramétrico chi-quadrado.

Segundo Fávero et al. (2009), a relação entre variáveis qualitativas se dá pela associação entre as frequências que podem ser explicitadas numa tabela de contingência, ou seja, pela associação entre as categorias das variáveis. Assim, procedeu-se a uma categorização das variáveis (indicadores econômico-financeiros) em dois grupos (maior e menor) a partir da identificação da mediana anual dos indicadores, de modo que os 2 valores abaixo da mediana seriam considerados de um grupo, com a menor magnitude do indicador econômico-financeiro analisado, enquanto que os 2 valores mais altos seriam categorizados no outro grupo, com a maior magnitude do indicador econômico-financeiro analisado. A Tabela 1 apresenta um exemplo dessa categorização em 2 dois grupos com os dados do indicador endividamento.

Tabela 1 - Exemplo de Categorização dos Indicadores Econômico-financeiros, Agrupados em Grupo 1

(G1) e Grupo 2 (G2). Indicador Apresentado: Endividamento

\begin{tabular}{cccccccc}
\hline Companhias & $\mathbf{2 0 1 3}$ & $\mathbf{2 0 1 4}$ & $\mathbf{2 0 1 5}$ & $\mathbf{2 0 1 6}$ & $\mathbf{2 0 1 7}$ & $\mathbf{2 0 1 8}$ & $\mathbf{2 0 1 9}$ \\
\hline Ânima (ANIM3) & 0,45 & 0,37 & 0,45 & 0,54 & 0,48 & 0,54 & 0,71 \\
Cogna (COGN3) & 0,36 & 0,26 & 0,25 & 0,21 & 0,19 & 0,48 & 0,54 \\
Yduqs (YDUQ3) & 0,29 & 0,32 & 0,39 & 0,41 & 0,31 & 0,37 & 0,44 \\
Ser Educacional (SEER3) & 0,44 & 0,50 & 0,59 & 0,53 & 0,40 & 0,39 & 0,49 \\
\hline Companhias & $\mathbf{2 0 1 3}$ & $\mathbf{2 0 1 4}$ & $\mathbf{2 0 1 5}$ & $\mathbf{2 0 1 6}$ & $\mathbf{2 0 1 7}$ & $\mathbf{2 0 1 8}$ & $\mathbf{2 0 1 9}$ \\
\hline Ânima (ANIM3) & 2 & 2 & 2 & 2 & 2 & 2 & 2 \\
Cogna (COGN3) & 1 & 1 & 1 & 1 & 1 & 2 & 2 \\
Yduqs (YDUQ3) & 1 & 1 & 1 & 1 & 1 & 1 & 1 \\
Ser Educacional (SEER3) & 2 & 2 & 2 & 2 & 2 & 1 & 1 \\
\hline
\end{tabular}

Fonte: Dados da pesquisa. 
Como pode ser observado na Tabela 1, no ano de 2013, Ânima e Ser apresentaram os 2 maiores valores de endividamento e, consequentemente, ambos acima da mediana que, no ano de 2013, foi de 0,40. Desta forma, foram categorizados como Grupo 2 que, como indicado anteriormente, representam o grupo com valor de maior magnitude no indicador econômicofinanceiro avaliado, neste caso, endividamento. Consequentemente, YDUQS e Cogna foram categorizadas, em 2013, no Grupo 1, ou seja, o grupo das companhias que apresentaram os menores índices de endividamento no ano. Pode-se observar que o mesmo procedimento foi realizado nos demais anos da amostra obtendo-se, assim, 28 observações companhia/ano para o indicador endividamento. Este procedimento foi realizado em todos os indicadores econômico-financeiros analisados na pesquisa.

O objetivo dessa categorização foi permitir a identificação de alguma relação entre o tipo de governança corporativa das companhias investigadas e os valores dos indicadores econômico-financeiros categorizados em grupos com maior e menor magnitude. A opção por utilizar variáveis qualitativas na análise se deu pelo fato de os dados não contemplarem características necessárias para a execução de técnicas estatísticas paramétricas, como a análise de variância e a regressão, aspecto que poderia gerar resultados enviesados ou com baixa robustez. Ressalta-se que apesar do teste chi-quadrado não identificar a correlação ou a causalidade entre as variáveis investigadas, pode-se recorrer à teoria como forma de interpretar as associações identificadas entre as categorias das variáveis analisadas, quais sejam, governança corporativa e indicadores econômico-financeiros (FÁVERO et al., 2009).

\section{Apresentação e discussão dos resultados}

Estruturou-se esta seção em três subseções. Na primeira e segunda subseções são apresentados os resultados relativos, respectivamente, à governança corporativa e aos indicadores econômico-financeiros. A terceira e última seção se dedica à discussão conjunta dos resultados.

\subsection{Governança corporativa: modelos anglo-saxônico e latino-americano}

A síntese dos resultados acerca das características definidoras de governança corporativa (ROSSETTI; ANDRADE, 2014) das quatro companhias listadas na $[\mathrm{B}]^{3}$ e, que fazem parte do setor educacional superior, é apresentada por meio da Tabela 2. Ressalta-se que os percentuais representam a média do período investigado. 
Tabela 2 - Características Definidoras de Governança Corporativa das Companhias Investigadas

\begin{tabular}{|c|c|c|c|c|c|}
\hline $\mathbf{N}^{\mathbf{o}}$ & $\begin{array}{l}\text { Característica } \\
\text { Definidora }\end{array}$ & Ânima & Cogna & Ser & YDUQS \\
\hline 1 & Segmento de listagem & Novo Mercado & Novo Mercado & Novo Mercado & Novo Mercado \\
\hline 2 & Composição acionária & $\begin{array}{l}\text { Concentrada } \\
71,62 \%\end{array}$ & $\begin{array}{l}\text { Pulverizada } \\
20,99 \%\end{array}$ & $\begin{array}{l}\text { Concentrada } \\
66,15 \%\end{array}$ & $\begin{array}{c}\text { Pulverizada } \\
33,75 \%\end{array}$ \\
\hline 3 & Fonte de financiamento & Equity $49,43 \%$ & Equity $67,29 \%$ & Equity $52,29 \%$ & Equity $63,86 \%$ \\
\hline 4 & Propriedade e controle & $\begin{array}{l}\text { Acionista } \\
\text { majoritário }\end{array}$ & CEO & $\begin{array}{l}\text { Acionista } \\
\text { majoritário }\end{array}$ & CEO \\
\hline 5 & Propriedade e direção & Sobreposta & Dissociada & Sobreposta & Dissociada \\
\hline 6 & Conflito de agência & Tipo II & Tipo I & Tipo II & Tipo I \\
\hline 7 & $\begin{array}{l}\text { Proteção minoritários } \\
\text { (tag-along) }\end{array}$ & $\begin{array}{l}\text { Regras do Novo } \\
\text { Mercado }\end{array}$ & $\begin{array}{l}\text { Regras do Novo } \\
\text { Mercado }\end{array}$ & $\begin{array}{l}\text { Regras do Novo } \\
\text { Mercado }\end{array}$ & $\begin{array}{c}\text { Regras do Novo } \\
\text { Mercado }\end{array}$ \\
\hline 8 & $\begin{array}{l}\text { Conselho de } \\
\text { administração }\end{array}$ & $\begin{array}{l}40,73 \% \\
\text { acionistas }\end{array}$ & $\begin{array}{c}13,59 \% \\
\text { acionista }\end{array}$ & $\begin{array}{c}38,10 \% \\
\text { acionista }\end{array}$ & $\begin{array}{c}6,35 \% \\
\text { acionistas }\end{array}$ \\
\hline 9 & $\begin{array}{l}\text { Liquidez ações (free } \\
\text { float) }\end{array}$ & $28,38 \%$ & $79,01 \%$ & $33,85 \%$ & $66,25 \%$ \\
\hline 10 & Forma de controle & Interna & Externa & Interna & Externa \\
\hline 11 & Modelo de governança & Shareholder & Stakeholder & Shareholder & Stakeholder \\
\hline 12 & $\begin{array}{l}\begin{array}{l}\text { Remuneração } \\
\text { executivos }\end{array} \\
\end{array}$ & $\begin{array}{l}\text { Variável } \\
32,27 \%\end{array}$ & $\begin{array}{l}\text { Variável } \\
41,33 \%\end{array}$ & $\begin{array}{l}\text { Variável } \\
32,28 \%\end{array}$ & $\begin{array}{l}\text { Variável } \\
37,68 \%\end{array}$ \\
\hline
\end{tabular}

Fonte: Dados da pesquisa.

A análise dos resultados apresentados na Tabela 2 permite identificar a formação de dois grupos. O primeiro, formado pela Cogna e pela YDUQS, possui características predominantes do modelo anglo-saxônico de governança corporativa. O segundo, formado pela Ânima e pela Ser possui características predominantes do modelo latino-americano (ROSSETTI; ANDRADE, 2014).

Das características definidoras analisadas é relevante destacar que todas as companhias pertencem ao segmento do Novo Mercado da $[\mathrm{B}]^{3}$. Este é um aspecto fundamental, pois estas instituições apresentam o mais elevando grau de governança corporativa, segundo os critérios da própria $[\mathrm{B}]^{3}$ (TAVARES; PENEDO, 2018). Com isso, é possível inferir a existência de determinado nivelamento entre a governança corporativa destas companhias, que precisam cumprir com requisitos legais e infralegais para se manterem neste segmento, como por exemplo, a adoção de mecanismos de proteção legal a acionistas minoritários.

A despeito deste nivelamento os dois grupos de companhias fizeram a opção de adotar configurações distintas de governança corporativa. O primeiro grupo, formado pela Cogna e pela YDUQS possui como características centrais a pulverização da composição acionária; a fonte predominante de financiamento do tipo equity; a dissociação entre a propriedade e a gestão; o controle sendo exercido pelo CEO; o conflito de agência do tipo I (entre o principal e o agente); e forças externas (mercado) de controle mais atuantes. Estas características fazem 
com que estas companhias possuam modelo mais alinhado com o anglo-saxônico (ROSSETTI; ANDRADE, 2014).

Por outro lado, o segundo grupo, formado pela Ânima e pela Ser possui como características centrais a concentração da composição acionária; a fonte predominante de financiamento equilibrada entre o equity e o debt; a sobreposição entre a propriedade e a gestão; o controle sendo exercido pelo acionista majoritário; conflito de agência do tipo II (entre acionistas majoritários e minoritários); e forças internas (concentração da propriedade) de controle mais atuantes. Estas características fazem com que estas companhias possuam modelo mais alinhado com o latino-americano (ROSSETTI; ANDRADE, 2014).

\subsection{Relação entre modelos de governança corporativa e os indicadores econômico- financeiros}

Tendo como referência os dois grupos de companhias identificados na subseção anterior, procede-se nesta subseção à análise da relação entre os modelos de governança corporativa e os indicadores econômico-financeiros apontados por Assaf Neto (2020). Inicialmente, torna-se relevante fazer algumas observações acerca da análise dos indicadores econômico-financeiros.

Considerando que a categorização dos diferentes indicadores de liquidez gerou variáveis praticamente idênticas, optou-se por analisar apenas o indicador Liquidez Corrente, considerado o mais importante deles (ASSAF NETO, 2020). Ressalta-se também que o indicador ROI (retorno sobre os investimentos) ficou com uma distribuição idêntica ao ROE (retorno sobre o patrimônio líquido), optando-se, assim, por utilizar apenas o segundo na análise. Os resultados dos testes chi-quadrado estão apresentados na Tabela 3.

Tabela 3 - Resultados do Teste Chi-Quadrado

\begin{tabular}{cccc}
\hline Relação entre a Governança Corporativa com: & $\boldsymbol{\chi}^{\mathbf{2}}$ & p-valor & Significativo \\
\hline Liquidez Corrente & 0,00 & 1,00 & Não \\
Prazo Médio de Receb. de Vendas & 2,29 & 0,13 & Não \\
Endividamento & $\mathbf{1 4 , 2 9}$ & $\mathbf{0 , 0 0}$ & Sim \\
Rentabilidade - ROE & 0,57 & 0,45 & Não \\
Rentabilidade - ROA & 0,00 & 1,00 & Não \\
Margem Oper. & 0,57 & 0,45 & Não \\
Margem Liquida & 2,29 & 0,13 & Não \\
Lucro por Ação & 0,57 & 0,45 & Não \\
Indice Preço-Lucro & 0,57 & 0,45 & Não \\
Índice Preço-Valor patrimonial & 0,57 & 0,45 & Não \\
Dividend Yield & $\mathbf{5 , 1 4}$ & $\mathbf{0 , 0 2}$ & Sim \\
Payout & 2,29 & 0,13 & Não \\
\hline
\end{tabular}

Fonte: Dados da pesquisa. 
Como pode ser observado na Tabela 3, somente os seguintes indicadores econômicofinanceiros apresentaram uma relação significativa com a variável governança corporativa: (1) endividamento (significativo a 1\%) e; (2) dividend yield (significativo a 5\%). Os demais indicadores não apresentaram significância estatística.

A Tabela 4 apresenta as tabelas de contingência da variável governança corporativa com os indicadores econômico-financeiros que apresentaram relação significativa. O teste chiquadrado estima os valores esperados em cada célula da tabela de contingência para que não haja associação entre as categorias das variáveis e os compara com os valores observados. Quanto maior a discrepância entre os valores esperados e observados, maior será a estatística $\chi^{2}$ e menor será o p-valor, aumentando a possibilidade de haver uma relação entre as variáveis.

Tabela 4 - Tabelas de Contingência entre a Governança Corporativa e os Indicadores Econômicofinanceiros Significativos

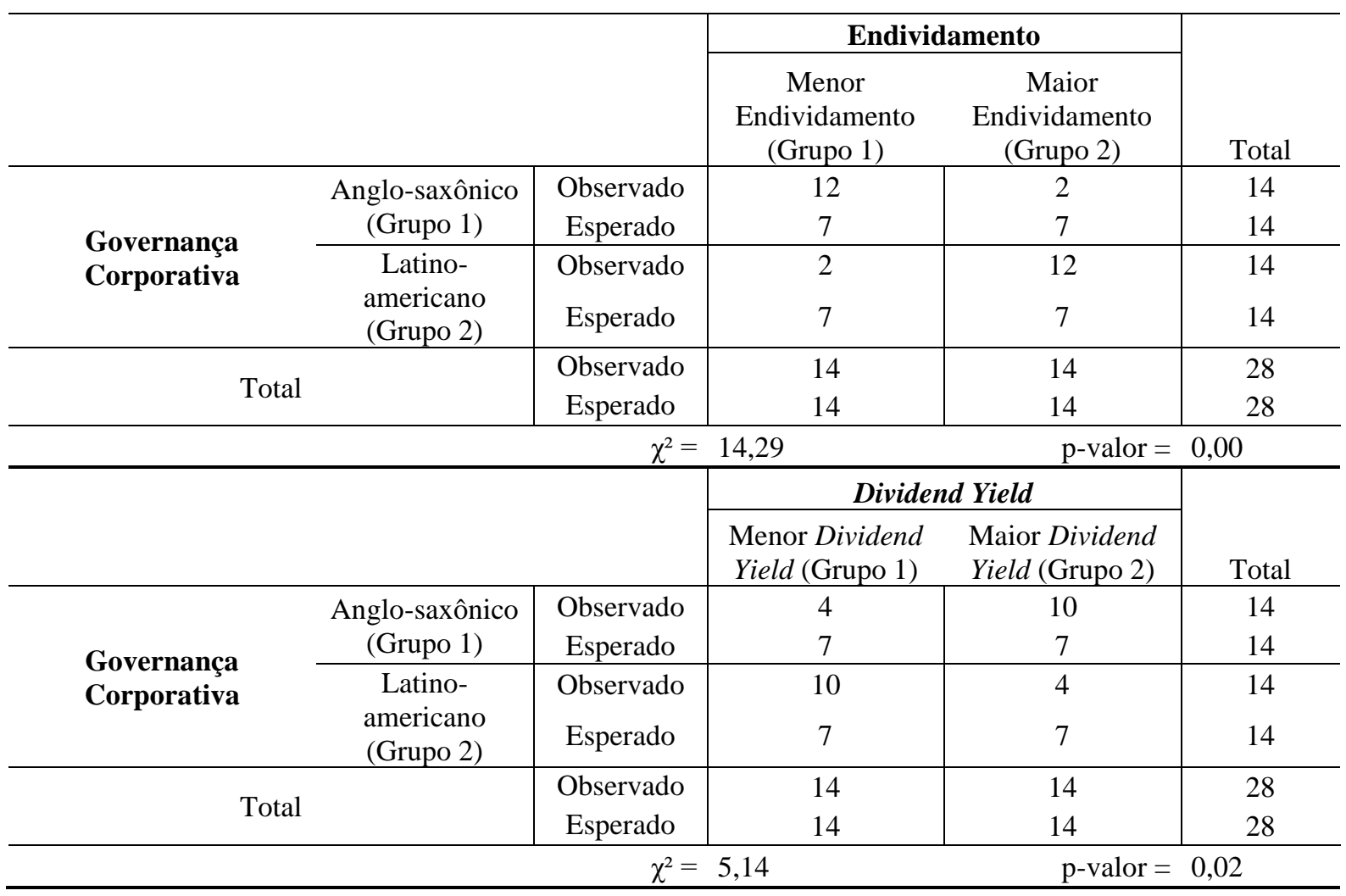

Fonte: Dados da pesquisa.

Como pode ser observado na Tabela 4, a maior parte (12) das observações anuais das companhias classificadas como o modelo anglo-saxônico de governança corporativa esteve associada a um menor grau de endividamento. O grupo destas companhias também possui a maioria (10) das suas observações anuais associadas com um maior dividend yield no período 
analisado. Esses resultados sugerem que a Cogna e a YDUQS, enquanto companhias com modelo de governança corporativa anglo-saxônico, de fato, diferenciam-se em relação a estes aspectos da Ânima e da Ser, que são caracterizadas pelo modelo latino-americano.

\subsection{Discussão dos resultados}

Ao se analisar a governança corporativa das companhias investigadas, observou-se a formação de dois grupos com modelos internacionais de governança corporativo distintos. $\mathrm{O}$ primeiro, tipicamente anglo-saxônico formado pela Cogna e pela YDUQS, e o segundo, tipicamente latino-americano formado pela Ânima e Ser (ROSSETTI; ANDRADE, 2014). A relação entre os dois grupos de companhias com modelos internacionais de governança corporativa distintos (anglo-saxônico e latino-americano) (ROSSETTI; ANDRADE, 2014) e os indicadores econômico-financeiros (ASSAF NETO, 2020) permitiu fazer comparações sobre a efetividade da governança corporativa destes dois grupos, considerando dois aspectos: endividamento e dividend yield.

Em relação ao endividamento, constata-se que o grupo que adota o modelo anglosaxônico utiliza menos capital de terceiros quando comparado com o outro grupo. Há um indicativo de que a Cogna e a YDUQS possuam maior capacidade para captar recursos via mercado de capitais, ou seja, via equity, quando comparado com a Ânima e a Ser.

Ao se observar o dividend yield é possível verificar que as companhias com modelo anglo-saxônico apresentam uma maior rentabilidade dos dividendos quando comparada com as companhias do modelo latino-americano. Neste caso, parece demonstrado que a Cogna e a YDUQS remuneram melhor os acionistas, ou seja, geram mais valor para os shareholders.

Esses resultados remetem à necessidade de se refletir sobre, pelo menos, quatro aspectos, quais sejam: ao mercado de capitais brasileiro, ao setor educacional superior presente na $[\mathrm{B}]^{3}$, ao modelo de governança corporativa das companhias investigadas e a relação entre os modelos de governança corporativa e os indicadores econômico-financeiros. Esses aspectos que possuem natureza sistêmica e relação de interdependência tem potencial para explicar, mesmo que parcialmente, os resultados encontrados na pesquisa.

O primeiro aspecto diz respeito ao mercado de capitais brasileiro que possui as seguintes características centrais: (1) ser considerado pequeno, em processo embrionário de desenvolvimento e com ausência de transparência (SARLO NETO et al., 2005; BORTOLON; SILVA JUNIOR, 2015); (2) contar com a presença de companhias cuja estrutura de propriedade é concentrada (SARLO NETO et al., 2005; LEAL; BORTOLON, 2009; CARVALHAL, 2014); 
e (3) verificar a presença de grupos familiares no conselho de administração das companhias (VELLOSO; GRISCI, 2014; COSTA et al., 2014). Essas características centrais indicam que as companhias presentes no mercado de capitais lidam com um contexto institucional ainda em formação quando comparado com mercados de capitais mais desenvolvidos como são os casos dos mercados dos EUA e do Reino Unido (YOUNG et al., 2008).

$\mathrm{O}$ segundo aspecto refere-se ao setor educacional superior presente na $[\mathrm{B}]^{3}$. Esse setor que atualmente conta com quatro companhias (entidades mantenedoras de IES) foi inaugurado na antiga BM\&FBovespa no ano de 2007 indicando tratar-se de um setor pequeno e com aproximadamente 14 anos de existência (SILVA JUNIOR et al., 2017b; SILVA JUNIOR et al., 2020). A despeito dessas características, as companhias presentes nesse setor possuem aproximadamente 416 IES mantidas e concentram aproximadamente $26 \%$ das matrículas na educação superior brasileira (SILVA JUNIOR et al., 2017b) evidenciando a sua relevância na educação superior brasileira e o seu amplo potencial de crescimento e de expansão, seja pela aquisição de novas entidades mantenedoras, seja pela abertura de capital de novas entidades mantenedoras por meio do processo de IPO.

O terceiro aspecto está relacionado ao modelo de governança corporativa das companhias investigadas. Das quatro companhias listadas na $[\mathrm{B}]^{3}$ constatou-se que duas possuem modelo de governança corporativa tipicamente anglo-saxônico e duas possuem modelo tipicamente latino-americano. Algumas evidencias de contexto acerca desses modelos revelam alguns aspectos interessantes e que podem sinalizar os rumos evolutivos desses modelos

Uma primeira evidência é o fato de que as companhias que adotam o modelo latinoamericano são mais recentes no mercado de capitais e as que adotam o modelo anglo-saxônico atuam no mercado de capitais há mais tempo. A segunda evidência é que as companhias que atualmente adotam o modelo anglo-saxônico, no passado, adotavam o modelo latino-americano com controle familiar. A terceira evidência é a existência de um indicativo que ao longo dos últimos anos, as duas companhias que adotaram o modelo latino-americano vêm diminuindo a concentração da participação acionária. Neste caso, essas três evidências sinalizam a existência de um processo evolutivo nos modelos de governança corporativa das companhias, que tem sua origem como modelo latino-americano com tendência a alcançar um estágio mais evoluído que é o modelo anglo-saxônico.

O quarto aspecto envolve a relação entre os modelos de governança corporativa e os indicadores econômico-financeiros. Os resultados indicam que no setor da educação superior brasileira presente na $[\mathrm{B}]^{3}$, os modelos de governança corporativa adotados pelas companhias 
não influenciam nos seus indicadores econômico-financeiros, exceção feita ao indicador de endividamento e ao indicador de mercado dividend yield. Em outros termos, o possível movimento evolutivo do modelo latino-americano para o modelo anglo-saxônico de governança corporativa influencia apenas (1) na capacidade das companhias de geração de caixa para suportar os juros e o principal de suas dívidas e/ou garantir o crescimento de suas atividades; e (2) na maior rentabilidade dos dividendos, ou seja, numa maior remuneração para os acionistas (ASSAF NETO, 2020).

Assim, os dados e os resultados da pesquisa evidenciam que tanto o mercado de capitais brasileiro quanto o setor da educação superior na $[\mathrm{B}]^{3}$ e os modelos de governança corporativa das companhias presentes nesse setor encontram-se em processo de evolução e crescimento. Possivelmente, essa dinâmica evolutiva possa explicar, mesmo que parcialmente, a ausência de relação entre os modelos de governança corporativa e os indicadores econômico-financeiros, ausência feita aos indicadores endividamento e dividend yield.

\section{Conclusões}

A proposta deste estudo foi identificar a relação entre os modelos de governança corporativa e os indicadores econômico-financeiros das quatro entidades mantenedoras de IES (companhias) presentes no mercado de capitais brasileiro. Para isso, realizou-se uma pesquisa documental com dados coletados por meio de triangulação e submetidos ao teste chi-quadrado.

A síntese dos resultados revela a formação de dois grupos de companhias, quais sejam, Grupo 1 e Grupo 2. O primeiro, formado pela Cogna e pela YDUQS adotam modelo de governança corporativa tipicamente anglo-saxônico. O modelo de governança corporativa adotado por essas companhias tem como características centrais (1) a presença de pulverização da composição acionária; (2) possuir como fonte predominante de financiamento o tipo equity; (3) a dissociação entre a estrutura de propriedade e a estrutura de gestão; (4) o controle da companhia sendo exercido pelo CEO; (5) a incidência do conflito de agência do tipo I (entre o principal e o agente); e (6) o predomínio de forças externas de controle como mais atuantes, ou seja, forças de mercado (ROSSETTI; ANDRADE, 2014).

O segundo grupo, formado pela Ânima e pela Ser adotam modelo tipicamente latinoamericano. O modelo de governança corporativa adotado por essas companhias tem como características centrais (1) a presença de concentração da composição acionária; (2) possuir como fonte predominante de financiamento um equilíbrio entre os tipos equity e debt; (3) a sobreposição entre a estrutura de propriedade e a estrutura de gestão; (4) o controle da companhia sendo exercido pelo acionista majoritário e controlador; (5) a incidência do conflito 
de agência do tipo II (entre acionistas majoritários e minoritários); e (6) o predomínio de forças internas de controle como mais atuantes, ou seja, a concentração da estrutura de propriedade (ROSSETTI; ANDRADE, 2014).

Ao proceder a análise destes dois grupos (Grupo 1 e Grupo 2) em termos dos indicadores econômico-financeiros, os resultados indicam que para as companhias presentes no setor da educação superior brasileira na $[\mathrm{B}]^{3}$, os modelos de governança corporativa não influenciam nos seus indicadores econômico-financeiros, exceção feita aos indicadores endividamento e dividend yield. Em relação a esses dois indicadores, os resultados sugerem que a estrutura de governança corporativa anglo-saxônica é mais efetiva quando comparada com a latinoamericana por proporcionar às companhias, (1) maior facilidade de captação de recursos para investimentos de longo prazo e (2) melhor rentabilidade aos acionistas. Com isso, há evidências de que o modelo de governança anglo-saxônica possui potencial para gerar maiores benefícios econômico-financeiros para as entidades mantenedoras que adotam esse modelo.

Em parte, esses resultados podem ser explicados por meio da relação sistêmica e de interdependência entre quatro aspectos centrais: (1) mercado de capitais brasileiro; (2) setor educacional superior presente na $[\mathrm{B}]^{3}$; (3) modelo de governança corporativa das companhias investigadas; e (4) relação entre os modelos de governança corporativa e os indicadores econômico-financeiros. A análise desses aspectos indica que o mercado de capitais brasileiro, o setor da educação superior na $[\mathrm{B}]^{3}$ e os modelos de governança corporativa das companhias investigadas ainda se encontram em processo de evolução e crescimento. Acredita-se que essa dinâmica evolutiva possa explicar, mesmo que parcialmente, a ausência de relação entre os modelos de governança corporativa e os indicadores econômico-financeiros, ausência feita aos indicadores endividamento e dividend yield.

Os resultados da pesquisa apresentam contribuições para o campo de estudos da gestão universitária de IES, sobretudo àquelas que se encontram no mercado de capitais. Por ser uma temática ainda recente, as discussões aqui empreendidas têm potencial para contribuir tanto para o desenvolvimento de estudos acadêmicos quanto para os atores sociais e econômicos presentes no mercado de capitais.

O estudo apresenta limitações sendo as principais relacionadas ao tamanho do setor educacional superior no mercado de capitais brasileiro e a limitada quantidade de observações que impossibilitam a realização de análises estatísticas mais robustas. Apesar destas limitações, a análise do setor tem se demonstrado relevante, sobretudo por considerar o impacto das quatro instituições no âmbito da educação superior brasileira. Espera-se que os resultados da pesquisa 
possam contribuir para a melhor compreensão do fenômeno da governança corporativa na gestão universitária de entidades mantenedoras de IES.

\section{Referências}

ASSAF NETO, Alexandre. Finanças corporativas e valor. 8. ed. São Paulo: Atlas, 2020.

BARREYRO, Gladys Beatriz. Mapa do ensino superior privado. Brasília: INEP, 2008.

BENIN, Maicon Manoel; DIEHL, Carlos Alberto; MARQUEZAN, Luiz Henrique Figueira. Determinantes da evidenciação de indicadores não financeiros de desempenho por clubes brasileiros de futebol. Estudios Gerenciales, Santiago de Cali, v. 35, n. 150, p. 16-26, 2019.

BERLE, Adolf Augustus; MEANS, Gardiner Coit. The modern corporation and private property. 11. ed. New Brunswick, NJ: Transaction Publishers, 2010.

BLAIR, Margaret Mendenhall. Ownership and control: rethinking corporate governance for the twenty-first century. Washington: Bookings Institutions, 1995.

BORTOLON, Patricia Maria; SILVA JUNIOR, Annor da. Delisting Brazilian public companies: Empirical evidence about corporate governance issues. Brazilian Business Review, Vitória, v. 12, Special Issues, p. 92-117, 2015.

BRENES, Esteban; MADRIGAL, Kryssia; REQUENA, Bernardo. Corporate governance and family business performance. Journal of Business Research, Oslo, v. 64, n. 3, p. 280-285, 2011.

BROCH, Caroline; BRESCHILIARE, Fabiane Castilho Teixeira; BARBOSA-RINALDI, Ieda Parra. A expansão da educação superior no Brasil: notas sobre os desafios do trabalho docente. Avaliação, Campinas; Sorocaba, SP, v. 25, n. 02, p. 257-274, 2020. Disponível em: https://www.scielo.br/j/aval/a/fpjrVCm9bJpPn6LNsGZGLPH/?lang=pt. Acesso em: 1 mar. 2021.

CARVALHAL, André. Do internationalized companies have better governance? Lessons from Brazil. European Accounting Review, London, v. 24, n. 10, p. 679-690, 2014.

COSTA, Cristiano Machado et al. Family management: creating or destroying firm value? Economics Bulletin, Nashville, v. 34, n. 4, p. 2292-2302, 2014.

DENZIN, Norman Kent. The research act: a theoretical introduction to sociological methods. 3. ed. New York, NY: Prentice Hall, 1989.

DINIZ, Rosa Virgínia; GOERGEN, Pedro Laudinor. Educação superior no Brasil: panorama da contemporaneidade. Avaliação, Campinas; Sorocaba, SP, v. 24, n. 03, p. 573-593, 2019. Disponível em: https://www.scielo.br/j/aval/a/KWJWLBpHPFjBKbzSXw7TStb/?lang=pt. Acesso em: 1 mar. 2021.

FÁVERO, Luiz Paulo Lopes et al. Análise de dados: modelagem multivariada para tomada de decisões. Rio de Janeiro: Elsevier, 2009. 
FRITSCH, Rosangela; JACOBUS, Artur Eugênio; VITELLI, Ricardo Ferreira.

Diversificação, mercantilização e desempenho da educação superior brasileira. Avaliação, Campinas; Sorocaba, SP, v. 25, n. 1, p. 89-112, 2020. Disponível em:

https://www.scielo.br/j/aval/a/nQ9WySh5STQddnpnvQyszwM/?lang=pt. Acesso em: 1 mar. 2021.

GAMA, Maria Eliza Rosa; SANTOS, João Timóteo de los. Gestão na educação superior e as avaliações de suas práticas. Avaliação, Campinas; Sorocaba, SP, v. 25, n. 02, p. 458-476, 2020. Disponível em:

https://www.scielo.br/j/aval/a/nQ9WySh5STQddnpnvQyszwM/?format=html. Acesso em: 1 mar. 2021.

GOMEZ-MEJIA, Luis; WISEMAN, Robert Maxwell; DYKES, Bernadine Johnson. Agency problens in diverce contexts: a global perspective. Journal of Management Studies.

Durham, v. 42, n. 7, p. 1508-1517, 2005.

HART, Oliver. Corporate governance: some theory and implications. The Economic Journal, Oxford, v. 105, n. 430, p. 678-689, 1995.

INEP - INSTITUTO NACIONAL DE ESTUDOS E PESQUISAS EDUCACIONAIS ANÍSIO TEIXEIRA. Sinopse estatística da educação superior 2019. Brasília: INEP, 2020.

IUDÍCIBUS, Sergio de. Análise de balanços.10. ed. São Paulo: Atlas, 2009.

JENSEN, Klaus Bruhn; JANKOWSKI, Nicholas Warren (eds.). Metodologias cualitativas de investigación en comunicación de masas. Barcelona: CIC-UCAB, 1993.

JENSEN, Michael Cole; MECKLING, William. Theory of firm: managerial behavior, agency costs and ownership structure. Journal of Financial Economics, Rochester, v. 3, n. 4, p. 305360, 1976.

LAMARRA, Norberto Fernández; BRÁ, Mariana Alonso. La gestión universitaria en la Argentina: una aproximación a partir de la evaluación institucional externa. In: COLOSSI, N.; SOUZA PINTO, M. D. (org.). Estudos e perspectivas em gestão universitária. Blumenau: Nova Letra, 2004. p. 21-34.

LA PORTA, Rafael; LOPEZ-DE-SILANEZ, Florencio; SHLEIFER, Andrei. Corporate ownership around the world. The Journal of Finance, Salt Lake City, v. 54, n. 2, p. 471-517, 1999.

LEAL, Ricardo Pereira Câmara; BORTOLON, Patrícia Maria. Controle compartilhado: impactos sobre o valor da firma. In: INSTITUTO BRASILEIRO DE GOVERNANÇA CORPORATIVA (org.). Governança corporativa: estrutura de controles societários. São Paulo: Saint Paul, 2009. p. 125-137.

LIMA, Natália Mendes et al. Fraudes corporativas e a formação de contadores: uma análise dos currículos dos cursos de ciências contábeis. Revista Ambiente Contábil, Natal, v. 9, n. 1, p. 97-116, 2017. 
MARQUEZAN, Luiz Henrique Figueira; DIEHL, Carlos Alberto; ALBERTON, J. R. Indicadores não financeiros de avaliação de desempenho: análise de conteúdo em relatórios anuais digitais. Contabilidade, Gestão e Governança, Brasília, v. 16, n. 2, p. 46-61, 2013.

MILLAR, Carla et al. Corporate governance and institutional transparency in emerging market. Journal of Business Ethics, Melbourne, v. 59, n. 1, p. 163-174, 2005.

MOGALAKWE, Monageng. The use of documentary research methods in social research. African Sociological Review, Makhanda, v. 10, n. 1, p. 221-230, 2006.

PAYNE, Geoff; PAYNE, Judy. Key concepts in social research. London: Sage Publications, 2004.

ROSSETTI, José Paschoal; ANDRADE, Adriana. Governança corporativa: fundamentos, desenvolvimento e tendências. 7. ed. São Paulo: Atlas, 2014.

SALES, Edriene Cristine da Silva Santos et al. O programa de apoio a planos de Reestruturação e Expansão das Universidades Federais (REUNI): uma análise de seu processo de avaliação. Avaliação, Campinas; Sorocaba, SP, v. 24, n. 03, p. 658-679, 2019. Disponível em: https://www.scielo.br/j/aval/a/TwXXdzXm9X9YFy7kkFdYYSn/?lang=pt. Acesso em: 1 mar. 2021.

SARLO NETO, Alfredo et al. O diferencial no impacto dos resultados contábeis nas ações ordinárias e preferenciais no mercado brasileiro. Revista Contabilidade \& Finanças, São Paulo, v. 16, n. 37, p. 46-58, 2005.

SILVA, Alexandre Alcântara da. Estrutura, análise e interpretação das demonstrações contábeis. 5. ed. São Paulo: Atlas, 2017.

SILVA JUNIOR, Annor da; MUNIZ, Reynaldo Maia; MARTINS, Priscilla de Oliveira. Governança corporativa na IES familiar de grande porte: um estudo de caso. Revista Alcance, Itajaí, v. 16, n. 3, p. 286-303, 2009.

SILVA JUNIOR, Annor da et al. Felicidade! passei no vestibular, mas a faculdade é particular: paradoxos da educação superior brasileira. Education Policy Analysis Archives, Tempe, Arizona, v. 25, n. 97, 2017a. Disponível em: https://epaa.asu.edu/ojs/article/view/2902/1960. Acesso em: 1 mar. 2021.

SILVA JUNIOR, Annor da et al. Demonstração de valor adicionado na Instituição de Educação Superior: evidências do mercado de capitais brasileiro. Revista Gestão Universitária na América Latina, Florianópolis, v. 10, n. 4, p. 22-46, Edição Especial $2017 b$.

SILVA JUNIOR, Annor da et al. Governança corporativa em Instituições de Educação Superior privadas: evidências do mercado de capitais brasileiro. Revista Gestão Universitária na América Latina, Florianópolis, v. 13, n. 3, p. 164-185, 2020.

SILVA JUNIOR, Annor da; QUILICE, Thiago Ferreira. Análise política da coevolução entre entidades que formam a arena política da educação superior brasileira: influências do processo político nas políticas públicas. In: ENCONTRO DOS ESTUDOS EM ESTRATÉGIA - 3ES, 9., Maringá, 2020, Evento On-line. Anais [...]. Maringá: Anpad, 2020. 
TAVARES, Vitor Borges; PENEDO, Antônio Sérgio Torres. Níveis de governança corporativa da B3: interesse e desempenho das empresas: uma análise por meio de redes neurais artificiais. Revista Contabilidade, Gestão e Governança, Brasília, v. 21, n. 1, p. 40$62,2018$.

TEIXEIRA, Elenice Cacia Bittencourt; MELO, Anderson Martins de. Índices-padrão de indicadores econômico-financeiros das empresas de capital aberto do seguimento de construção civil integrantes do novo mercado. In: CONGRESSO UFSC DE INICIAÇÃO CIENTÍFICA EM CONTABILIDADE, 4., 2011, Florianópolis. Anais [...]. Florianópolis, UFSC, 2011.

VELLOSO, Simone Pitten; GRISCI, Carmem Ligia Iochins. Governança corporativa e empresas familiares em processo sucessório: a visão de consultores e de famílias empresárias. BASE - Revista de Administração e Contabilidade da Unisinos, São Leopoldo, RS, v. 11, n. 4, p. 367-381, 2014.

YOUNG Michael N. et al. Corporate governance in emerging economies: a review of the principal-principal perspective. Journal of Management Studies, Durham, v. 45, n. 1, p. 196-220, 2008. 